\title{
Population and housing census in the Caribbean Community - Key challenges
}

\author{
Philomen Harrison \\ Caribbean Community (CARICOM) Secretariat, Georgetown, Guyana \\ Tel.: +592 2220001 6; Fax: +592 222 0097; E-mail: pharrison2004@yahoo.com
}

\begin{abstract}
Small Island Developing States (SIDS) like those of the Caribbean Community are subject to a number of challenges that include susceptibility to external economic and financial shocks, vulnerability to natural disasters and to the effects of Climate Change that when combined with domestic policy choices lead to reduced funding for Development. This key constraint, affects the availability of resources for statistical development and specifically for the conduct of the decennial Population and Housing Census. In addition to the specific challenges that affect the entire census operations such as-political factors, accessibility to the households that are be enumerated and Crime, the efficiency of the census operation and the quality and timeliness of the results require intensive attention to enable a successful outcome.
\end{abstract}

Keywords: SIDS, financial-constraints, regional-coordination

\section{Introduction}

The Caribbean Community (CARICOM) consists of Small Island Developing [and Low-lying] States (SIDS). As SIDS, these countries face economic and environmental vulnerabilities including Natural Disasters and External Economic and Financial Shocks. Hurricanes have flattened islands across the Caribbean over the years with a ferocity occurring in recent years such as Hurricanes Irma and Maria of 2017 and Dorian this year.

From the economic perspective there are economic and social challenges arising out of the global economic and financial crises of the $2007 / 2008$ period that still impact CARICOM SIDS, along with economic challenges of domestic origin. The extreme weather conditions that are occurring with a fair degree of regularity across the wider Caribbean, serve to further intensify and exacerbate the poor state of affairs of the economies of SIDS. The outcomes include, fiscal and external deficits, increased poverty, food insecurity and unemployment that impact the economic and financial viability of these countries. Fundamentally, the achievement of sustainable growth and development in SIDS are affected, which in turn negatively impact the resources available to fund the development of the national statistical systems (NSS) such as for the execution of censuses and surveys.

Most of the countries of the CARICOM will be executing the 2020 Round of Population and Housing Census during the years 2020-2022. This is with the exception of Bermuda that conducted its Census in 2016, using a shortened questionnaire and Haiti that planned to undertake its census around 2020 but for the unrest taking place in that country.

While the Population and Housing Census is widely recognized for providing data for the strengthening of the entire NSS, the issues and challenges faced by CARICOM SIDS, directly or indirectly, impact the conduct of the census activity. In what follows, Section 2 further explores some of the general challenges faced by CARICOM SIDS that impact the production of statistics and highlights cooperation in statistics through the Standing Committee of Caribbean Statisticians and the regionally-coordinated approach used to assist countries. Section 3 focuses on the experiences and challenges that affect the conduct of Population and Housing Censuses. Strategies, Initiatives and opportunities that serve to mitigate the challenges are presented in Section 4. Conclusions follow in Section 5. 


\section{Census taking in CARICOM- the regionally-coordinated approach}

Small Island Developing States (SIDS) such as those of CARICOM are developing countries that face unique development challenges due to small size, narrow resource base, high susceptibility to external economic and financial shocks, vulnerability to natural disasters and to other environmental threats such as the effects of climate change. As a consequence, these challenges faced by SIDS impact the growth trajectory of the countries, the levels of living of the population and are manifested through a number of social, economic and environmental problems.

In so far that these issues affect growth and development they also impact domestic funding available for development including statistical development. Difficulties are therefore experienced by National Statistical Offices (NSO) in CARICOM SIDS in implementing updates in international statistical standards and in producing new areas of statistics. Specifically, the conduct of the largest statistical activity a country can undertake, the decennial population and housing census, is impacted, relative to the availability of adequate funds in a timely manner for the intensive preparatory work required at the outset of this exercise, to treat with the complexity of the field enumeration and the processing and analysis and dissemination of the census results.

It has long been recognized in the CARICOM that regional cooperation in statistics of such small countries can assist in bolstering the impact of small size and the other challenges. In this regard, from the commencement of the regional integration agenda in CARICOM in 1974, the important role of statistics was recognized, with the establishment and endorsement of the Standing Committee of Caribbean Statisticians (SCCS) at the Inaugural Meeting of the Conference of Heads of Government of CARICOM. The main objective of the SCCS is to achieve functional cooperation in statistics, specifically, "to foster increased recognition of the importance of adequate statistical services to the countries of the region, to widen the scope and coverage of statistical data collection and to improve the quality, comparability and timeliness of the statistics produced".

Almost, 45 years after the establishment of the SCCS, political support to statistics in CARICOM was again revived, when the $39^{\text {th }}$ Regular Meeting of the Conference of Heads of Government (HGC) of the Caribbean Community (CARICOM) endorsed the
CARICOM Regional Strategy for the Development of Statistics (RSDS). This endorsement by the $39^{\text {th }}$ HGC was preceded at the $38^{\text {th }}$ HGC of the approval of the preparation of the CARICOM RSDS. The Action Plan for Statistics in the Caribbean was also endorsed at the $37^{\text {th }}$ HGC in 2016 that reflected the needs of monitoring the 2030 Agenda for Sustainable Development that requires the production of approximately $230+$ Sustainable Development Goals (SDG) indicators.

The regionally-coordinated strategy for the 2020 Population and Housing Census is a key aspect of the RSDS, based on the recognition of the census as an integrated statistical programme that is a critical source of data for the production of a wide range of official statistics throughout the NSS.

However, a regionally-coordinated approach to census-taking has been a tradition dating back to the colonial area and specifically among the British colonies in the Caribbean. A major turning point in more intensive census coordination occurred in 1966 when the Commonwealth Caribbean Statisticians met for the first time and established a Census Coordinating Committee that was used for the 1970 Census Round in supporting the efforts of countries. Further, in 1976, the Commonwealth Caribbean Statisticians at their Ninth Meeting recommended that the CARICOM Secretariat and the Community Council of Ministers agree to the following:

- The establishment of a Regional Census Coordinating Committee (RCCC).

- Mandated that the CARICOM Secretariat organize and convene meetings of the RCCC and produce and execute a Regional Census Strategy.

These decisions have been implemented from the 1980 Census Round to the current round of censuses, 2020.

\section{The CARICOM Statistical System (CSS) - Challenges that impact the census}

In CARICOM SIDS, the national statistical systems (NSS) comprise National Statistical Offices (NSOs) of varying sizes and positioning within the hierarchy of the government service and other Producers of Statistics in Ministries, Departments and Agencies (MDAs) of Member States and Associate Members. The CARICOM Statistical System (CSS) comprises the NSS and the Regional Statistics Programme (RSP) of the CARICOM Secretariat. 
Diagnostic assessments have been conducted of the NSOs in 2011/2012 and also in 2016/2017 during the preparation of the CARICOM RSDS. These assessments show that the staff-size of these offices ranged from 5 to 357 , with 53 percent having a size of just under 50 and 88 percent being under 110 in the countries responding to the 2011/2012 assessment. For the more recent assessment these figures were not much different, ranging from about 5 to 300 with similar percentages as in 2011/2012.

The NSOs differ in the quantum and quality of statistical outputs and in their capacity to be the coordinator of the NSS. The level of priority given to statistics by governments, reflected in the positioning of the NSOs within the public service, has implications for the funding of the activities they need to inform the social, economic and environmental issues that require measurement.

Like NSSs world over these small offices are facing an ever-increasing demand for statistics including more recently for monitoring the 17 goals and 169 targets of the 2030 Agenda for Sustainable Development comprising some $230+$ indicators. In addition, the monitoring of the SIDS Accelerated Modalities of Action, the Samoa Pathway must also be undertaken by CARICOM SIDS as well as the flagship regional integration framework - the CARICOM Single Market and Economy (CSME).

In effect, these small NSOs are faced with the need to measure an increasing number of phenomena in a timely and more urgent manner than ever before.

A critical activity undertaken by the NSOs is the Population and Housing Census which is one of the core integrated programmes that permeates the production of statistics in the entire NSS, such as, the building of sampling frames for surveys, the conduct of an agricultural census, computation of indicators that inform economic, gender, social, environmental and information communication technology statistics and the very important area of demographic statistics and analysis.

Key challenges of the NSOs that impact the Census as well as other statistical activities include:

1. Financial constraints: Inadequate financial resources that impact the entire NSO, inclusive of the ability to provide for basic elements such as staffing and accommodation. Generally there is great reliance on national or regionally funded projects from International Development Partners (IDPs).

2. Outdated organisational structure dating back to the 1970s for some countries, that has not kept pace with the expanding demand for statistics, and the lack of capacity, based on the outdated staff structure, required to move into new areas of statistics and to coordinate the NSS.

3. Outdated statistics legislation that dates back to the immediate post-colonial/independence period for some countries - appropriate statistics legislation is a key enabling factor that impacts the operations of the NSO and its ability to effectively coordinate the national statistical system. This issue is generally now being addressed through an IDB-funded project output that produced a CARICOM Model Statistics Bill that is being used by countries to update their Statistics Acts.

4. An IT infrastructure in need of upgrading to provide state-of the art applications and equipment that can yield increased efficiency in statistics production and dissemination, the ability to tap into new and non-traditional data sources and specifically to promote the use and analysis of the wide range of data and topics obtained from the Census;

5. Low ratio of professional to non-professional staff: experts in the fields of sampling, gender and seasoned demographic experts are getting rare in CARICOM countries. Training in demography was undertaken in the past, but advanced level and continuous training are required to better equip the NSOs in this area. The skill sets of the NSOs should also reflect data scientists required to navigate and make sense of big data sources.

6. Over reliance on short-term delegated authority staff in contrast to appointment of permanent staff on the establishment. Staff under delegated authority are temporary contract staff that can be appointed by the Director of Statistics for shortterm activities.

7. Inadequate accommodation. In the case of one NSO it had to vacate its main accommodation due to issues pertaining to health and safety of the building. Many of the staff could not be housed in the remaining building of the NSO (a former census office) and were at home for a long period. However, there has been some measure of improvement in accommodation in some of the NSOs in recent years.

Despite the above key challenges the NSOs continue to produce data and to undertake the Census exercise when these are due. In this regard, the census being 
such a large and complex exercise and given the level of statistical development of CARICOM countries including the statistical culture of the population, there are a number of specific challenges that are manifested during the conduct of the Census. These challenges are discussed in what follows.

\subsection{Political factors}

Political factors were identified as impediments to the conduct of past censuses to varying degrees across countries. These factors are normally manifested through changes in support to the NSOS with changes in governments over the inter-censal period. Lack of cooperation of political parties that were formerly in power and are not in power during the census hampers the coverage of the census. Relative to the budgetary process, delays and difficulties in the transferring of funds from the budget divisions of the Government for census activities impact the efficiency of the census process and the timeliness of dissemination of the results. However budgetary challenges may be independent of the politics in some cases.

An additional challenge under political factors, is that of the political directorate sending persons for employment as enumerators and supervisors that are not qualified and who cannot be trained to function in these positions.

There have also be instances when the NSO has planned and scheduled the census operation and the Government then calls a general election which has led to the postponement of the Census.

\subsection{Problems of access}

Remote areas, gated communities and special population groups are some issues under this area. Access to households in remote areas to undertake enumeration poses a number of challenges. One of the key issues mentioned was the issue of transportation to undertake the interview in remote areas. This issue also posed a risk relative to the safety of the enumerator in these remote areas.

Additionally, in countries like Suriname and Guyana that contain, what is known as "interior" regions, which are parts of the country that are very remote, special arrangements have to be made to access these regions, which may include use of a plane or a boat along with miles of walking to reach these population groups. This enumeration in the interior must also be done before the rainy season else the paths are impass- able. Adverse climatic condition is therefore a factor that negatively impact access for enumeration.

Related to access is the issue of the transient nature of the population in the interior, including indigenous groups and gold-miners who are difficult to locate.

Ensuring safety of the interviewers in areas that are difficult to access and the issue of insufficient daylight hours are also features related to access to households for census-taking.

Forested areas where immigrant or undocumented population may be found also pose difficulty in terms of access.

Countries that comprise other islands also experience difficulties relative to access to the islands to enumerate the households. On the one hand, it could be the issue of physical access and on the other the issue of lack of access to the high-income population on some of these islands.

The challenge of gaining access to gated communities also arises. Residents of these gated communities are often suspicious of persons from outside their communities and do not give access to be enumerated. This issue is also related to that of crime.

There is also a challenge of enumerating the nonsheltered population that are not found in housing units. In some cases there are mental health issues that render enumeration impossible.

\subsection{Crime prone areas}

In many countries there is a problem with crime that impacts the census relative to enumerators not being able to access highly volatile areas that have a high degree of crime and gang warfare. It is not safe for the enumerators that are not resident in these areas to enter.

The flip side is that there are instances where criminal elements outfitted with census precepts pretend to be enumerators and gain entry to households for the purposes of criminal acts. This challenge impacts coverage including in gated communities mentioned earlier since there is tremendous suspicion of the enumerators.

\subsection{Other challenges}

This item is a "catch-all" for a number of other challenges that are specific to the region. The ability to have an appropriate organisational structure for the census is a key issue for SIDs. It is linked to the issue of having the budget for the census available in a timely manner or at all. The availability of persons that can func- 
tion as enumerators, supervisors is also an issue which is often linked to political factors as mentioned earlier since persons that are ill-suited to the undertaking may be sent by the politicians for employment.

Training is another critical issue and is often reflected in the inability of recruits to read and understand the manuals, maps, census documents, a general lack of commitment of these persons and illegible handwriting.

The above are some of the key specific issues which in addition to the broader issues that impact SIDS relative to its overall statistical development, directly affect the census undertaking impacting the quality and coverage of the data.

\section{Strategies applied to mitigate challenges}

At a meeting of census experts in 2000 held in Jamaica, under the regionally-coordinated census strategy for that census round, a number of challenges were identified and good practices were discussed and outlined to circumvent these challenges. Evidently, issues such as the lack of finance which impact the census budget, the unwillingness of sub-populations to respond may prove to be more intractable to circumvent than some of the other challenges. Additionally, the annual Regional Census Coordinating Committee meetings for the 2010 census round and the Census Symposium of 2014 provided additional information on the challenges and strategies used during the last census round. Among the strategies used to enable the conduct of enumeration were the following:

1. Strategy to treat with lack of access due to transportation: To overcome the transportation difficulties faced by interviewers in accessing remote areas the initiatives included: the utilization of official vehicles owned by the National Statistical Office to transport the interviewers to the remote areas; provision of additional funds to enable them to cover their transportation costs and employing supervisors that owned vehicles to assist in transporting the interviewers to remote areas.

2. Strategy to gain access to remote interior regions of countries: In countries like Guyana and Suriname that as mentioned earlier have vast remote areas known as the "interior", there was a reliance on ferries, the chartering of boats and planes (as well as use of commercial planes), use of "all-terrain vehicles" and lengthy walking to reach some of these interior regions.
3. General Strategy used in some remote regions: The construction of camp sites for field staff in remote regions was also a strategy undertaken to gain access to remote areas.

4. Strategy to access transient sub-populations: Accessing transient sub-populations entailed recruiting persons from the community to work as guides and to assist in locating these subpopulations or undertaking a fly-over at least two weeks before enumeration to confirm the location of these transient population groups.

5. Strategy to access gated communities: Access to Gated Communities was dealt with at the initial planning stages through making contact to trusted residents from these areas to obtain information that may allow access to these communities. There was increased publicity to inform community members on the importance of the Census. Profiles were prepared of the area using information from the past census. Contact was also made with the residents through property managers of these communities or through various associations to which they may belong such as private sector/commerce associations. It was also necessary to make appointments in advance of any such visits to these communities.

6. Crime-Prone Areas: For Crime-Prone Areas, persons that were residents in these areas were used as interviewers. In the case of one NSO, there were persons that were employed at that NSO who were from a specific community and they were able to canvass the households. The NSO was also advised in this case not to use the police service or other security details to accompany the interviewers or to have them (police/security) be seen in the vicinity of the places being enumerated.

7. Approach to "Community Leaders": The NSO also approached "community-leaders" in these crime-prone areas to "obtain permission" from them to proceed with enumeration. Without this step it would not have been possible to proceed with enumeration.

8. Use of Team of interviewers with police protection: For some crime prone areas, it was possible to use teams of interviewers to undertake the interviews. Unlike for the strategy listed earlier, it was possible to have police protection for some crime-prone areas.

9. Political Factors: The strategy was to ensure that all political parties and all stakeholders are in- 
volved early in the census process and are equally represented. With respect to the recruitment process, the long-term more permanent strategy that was recommended was to make the NSOs more autonomous so that they have control over recruitment. A short-term strategy was the administering of a test that persons wishing to be employed as interviewers must pass.

10. Budgetary issues: With respect to the budgetary issues, it was indicated that engagement with the budget division responsible for the release of funds at a very early stage of the preparation of the budget was the recommended strategy. Establishment of financial arrangements for speedy disbursements was another strategy that was identified.

The sharing of these practices across the region under the regionally-coordinated CARICOM census strategy provides methods that countries can use to increase coverage of the population in the census.

\section{Conclusion}

Small Island Developing States face a number of unique challenges in conducting the Population and Housing Census. While it would seem that given the relatively small populations, the conduct of the census should be routine, the opposite is true based on the experiences during the census exercises. The regionallycoordinated approach that entails the coming together of countries to solve common problems, to learn from one another and to enable functional co-operation provides a knowledge-oriented mechanism whereby challenges faced in census-taking are aired, and good practices to mitigate the impact of these challenges are discussed and shared among countries.

The documentation of these strategies that was attempted for the 2000 census round out of a special meeting of census experts can be uprated based on information available in more recent rounds that may identify new challenges, or new aspects of old challenges. As an example, all CARICOM countries plan on utilising Computer Assisted Personal Interviewing Techniques (CAPI) to undertake census data capture. The CAPI approach is already being discussed among countries ranging from issues on the choice of the device, the number of edit checks to be included at the data capture stage and thefts of the devices/safety of the enumerators.

Already countries are discussing challenges that can circumvent these emerging issues including limiting the real-time edit checks, cost versus reliability issues in the choice of the devices and the use of paper-based questionnaires in some areas to mitigate thefts and safety issues.

It is likely that the experience of census taking in the 2020 round will bring new challenges and will stimulate solutions that can mitigate many of the challenges.

The use of a regionally-coordinated approach in CARICOM inclusive of initiatives such as: effective documentation of the challenges and the strategies and good practices, the convening of regional training workshops, the facilitating of South-South Cooperation, networking, the establishment of an online knowledge base and networking facility and the traditional medium of the Regional Census Coordinating Committee meetings that are held at least twice a year during the "census season", when combined, can serve to find solutions to common problems and challenges in CARICOM countries.

\section{References}

[1] Department of Economic and Social Affairs United Nations, Principles and Recommendations for Population and Housing Censuses, United Nations, Revision 3, 3017.

[2] United Nations Sustainable Development Goals [online homepage]. 